\title{
Feeding Regulates the Expression of Pancreatic Genes in Gastric Mucosa
}

\author{
Maria Rita De Giorgio, Mayumi Yoshioka, and Jonny St-Amand \\ Functional Genomics Laboratory, CREMOGH, CRCHUQ, and Department of Molecular Medicine, Laval University, \\ 2705 Boulevard Laurier, Quebec city, QC, Canada G1V 4G2
}

Correspondence should be addressed to Jonny St-Amand, jonny.st-amand@crchul.ulaval.ca

Received 5 September 2010; Revised 19 November 2010; Accepted 23 November 2010

Academic Editor: Xu Feng Huang

Copyright ( 2010 Maria Rita De Giorgio et al. This is an open access article distributed under the Creative Commons Attribution License, which permits unrestricted use, distribution, and reproduction in any medium, provided the original work is properly cited.

\begin{abstract}
The ineffective short-term control of feeding behavior compromises energy homeostasis and can lead to obesity. The gastrointestinal tract secretes several regulatory peptides. However, little is known about the stomach peptide contribution to the acute regulation of intake. In an attempt to identify new gastric signals, the serial analysis of gene expression (SAGE) method was used for the transcription profiling of stomach mucosa in 7 groups of mice: fasting and sacrificed 30 minutes, 1 hour, 3 hours after a low-fat (LF) or high-fat (HF) ad libitum meal. In total, 35 genes were differentially modulated by LF and HF meals compared to fasting, including 15 mRNAs coding for digestive enzymes/secretory proteins, and 10 novel transcripts. Although the basic expression profile did not undergo substantial variations, both LF and HF meals influenced the transcription. This study represents the first global analysis of stomach transcriptome as induced by different nutritional stimuli. Further studies including the characterization of novel genes may help to identify new targets for the therapy and prevention of obesity.
\end{abstract}

\section{Introduction}

Obesity epidemic continues its worrying global progression although significant advances have been achieved in the knowledge of its causes and consequences. This condition, in concert with glucose intolerance/type 2 diabetes, dyslipidemia, and metabolic syndrome, widely contributes to what has been recently defined as "prosperity's plague" [1]. A complex system of social, psychological, physiological, and biological factors has to be considered in order to successfully control this "plague" and prevent from its further spread $[2,3]$. From a physiological point of view, it is fundamental to understand the specific relative importance of long-term and short-term mechanisms involved in the regulation of energy balance [4]. Food intake and daily overconsumption may have a predominant impact on body weight regulation, and this led large interest to focus on appetite/satiety balance as one of the key potential therapeutic targets [5]. Multiple sites in the gastrointestinal (GI) tract, including the stomach, proximal and distal small intestine, colon, and pancreas, are involved in the short-term regulation of energy homeostasis, which basically controls what, when, and how much we eat within a single day or a single meal [6]. In addition to mechanoreceptors and chemoreceptors, which are activated during a meal and signal to the brainstem through the vagal nerve [4], several gut-derived peptides and lipid mediators have a role in the regulation of food intake and energy homeostasis [7]. The only recognized "hunger" gut peptide so far discovered is ghrelin. This peptide is mainly produced by the stomach and directly influences the number of meals consumed per day though it has probably no direct effect on meal size [8]. However, the stomach plays an essential mechanical role in the regulation of satiety perception and meal termination. It is, in fact, the first organ to receive the bolus of food. Here, the food ingested is rapidly homogenized, partially digested, and finally delivered to the small intestine. Importantly, gastric distension and gastric emptying via the pylorus are finely regulated in order to match food delivery to the actual gut digestive and absorptive capacity [9]. As a consequence, gastric competence can be considered as the first limiting step of GI ingestive and digestive capacity and thus represents a relevant target for obesity 
TABle 1: Transcripts coding for digestive and secretory proteins differentially modulated by feeding in the gastric mucosa.

\begin{tabular}{|c|c|c|c|c|c|c|c|c|c|c|c|c|c|c|c|}
\hline \multirow{2}{*}{ Tag } & \multirow{2}{*}{ Fasting } & \multicolumn{6}{|c|}{ Low fat } & \multicolumn{6}{|c|}{ High fat } & \multirow{2}{*}{\multicolumn{2}{|c|}{ Description }} \\
\hline & & $30 \mathrm{~min}$ & & $1 \mathrm{~h}$ & & $3 \mathrm{~h}$ & & $30 \mathrm{~min}$ & & $1 \mathrm{~h}$ & & $3 \mathrm{~h}$ & & & \\
\hline \multicolumn{16}{|l|}{ Digestive enzymes } \\
\hline CTGACTCAAAA & 713 & 86 & $\downarrow$ & 48 & $\downarrow$ & 2020 & $\uparrow$ & 383 & $*$ & 106 & $\downarrow$ & 70 & $\downarrow$ & * & $\begin{array}{l}\text { Amylase 2a1, pancreatic } \\
\text { (Mm.439729; NM_001042712) }\end{array}$ \\
\hline CCCTGGGTTCA & 130 & 4 & $\downarrow$ & 2 & $\downarrow$ & 353 & $\uparrow$ & 72 & $*$ & 14 & $\downarrow$ & $\mathbf{0}$ & $\downarrow$ & * & $\begin{array}{l}\text { Chymotrypsinogen B1 } \\
(\mathrm{Mm} .34374 ; \mathrm{BC} 061083)\end{array}$ \\
\hline TTAGGAGGCTG & 164 & 11 & $\downarrow$ & 6 & $\downarrow$ & 346 & & 72 & $*$ & 12 & $\downarrow$ & 2 & $\downarrow$ & * & $\begin{array}{l}\text { Pancreatic lipase (Mm.20407; } \\
\text { NM_026925) }\end{array}$ \\
\hline GGCTGTAATGT & 65 & 6 & $\downarrow$ & 6 & $\downarrow$ & 175 & & 52 & $*$ & 8 & $\downarrow$ & 7 & $\downarrow$ & $*$ & $\begin{array}{l}\text { Elastase 1, pancreatic (Mm.2131; } \\
\text { NM_033612) }\end{array}$ \\
\hline GTGTGCGCCGG & 61 & 4 & $\downarrow$ & 2 & $\downarrow$ & 117 & & 32 & & 2 & $\downarrow$ & 0 & $\downarrow$ & * & $\begin{array}{l}\text { Elastase 3, pancreatic } \\
(\mathrm{Mm} .297477 ; \text { BC061066) }\end{array}$ \\
\hline TTCTGTCTGGG & 51 & 0 & $\downarrow$ & 6 & $\downarrow$ & 102 & & 18 & & 2 & $\downarrow$ & $\mathbf{0}$ & $\downarrow$ & * & $\begin{array}{l}\text { Trypsinogen } 7 \text { ( RIKEN cDNA } \\
\text { 2210010C04 gene; } \\
\text { Mm.153729; BC061093) }\end{array}$ \\
\hline CCCGGGTGCAA & 0 & 4 & & 4 & & 36 & $\uparrow$ & 8 & & 0 & & 2 & & * & $\begin{array}{l}\text { Pancreatic lipase related protein } \\
1 \text { (Mm.10753; BC068266). }\end{array}$ \\
\hline GACCACACTGT & 35 & 6 & & 0 & $\downarrow$ & 109 & & 28 & & 10 & & 0 & $\downarrow$ & * & $\begin{array}{l}\text { Carboxypeptidase A1 } \\
(\mathrm{Mm} .25377 ; \mathrm{BC} 052661)\end{array}$ \\
\hline GAGCACGTACG & 14 & 0 & & 0 & & 36 & & 4 & & 0 & & 0 & & * & $\begin{array}{l}\text { Carboxypeptidase A2, pancreatic } \\
\text { (Mm.268855; NM_001024698) }\end{array}$ \\
\hline ATCTGTGTTGG & 193 & 27 & $\downarrow$ & 31 & $\downarrow$ & 317 & & 68 & & 37 & $\downarrow$ & 25 & $\downarrow$ & * & $\begin{array}{l}\text { Protease serine } 2 \text { (Mm.276926; } \\
\text { NM_009430)/Trypsin } 4 \\
\text { (Mm.383263; NM_011646) }\end{array}$ \\
\hline GCCTACAACTA & 30 & 0 & $\downarrow$ & 4 & & 113 & $\uparrow$ & 16 & & 2 & $\downarrow$ & 0 & $\downarrow$ & * & $\begin{array}{l}\text { Chymotrypsin-like (Mm.2745; } \\
\text { NM_023182) }\end{array}$ \\
\hline GCACCAAGTAC & 26 & 0 & $\downarrow$ & 0 & $\downarrow$ & 98 & $\uparrow$ & 16 & & 2 & & 2 & & * & $\begin{array}{l}\text { EST Carboxypeptidase B1 } \\
\text { (Mm.34692; CF577795) }\end{array}$ \\
\hline CAGACTAAGTA & 24 & 4 & & 2 & & 122 & $\uparrow$ & 26 & & $\mathbf{0}$ & $\downarrow$ & 2 & & & $\begin{array}{l}\text { Carboxyl ester lipase } \\
\text { (Mm.236017; NM_009885) }\end{array}$ \\
\hline \multicolumn{16}{|l|}{$\begin{array}{l}\text { Exocytosis/secretory } \\
\text { pathways }\end{array}$} \\
\hline GCAAGACCCGC & 26 & 2 & & 0 & $\downarrow$ & 49 & & 16 & & 2 & & 5 & & 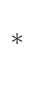 & $\begin{array}{l}\text { Syncollin (Mm.25210; } \\
\text { NM_026716) }\end{array}$ \\
\hline AAAGTATGCAA & 122 & 25 & $\downarrow$ & 37 & $\downarrow$ & 98 & & 72 & & 37 & $\downarrow$ & 34 & $\downarrow$ & & $\begin{array}{l}\text { Zymogen granule membrane } \\
\text { protein } 16 \text { (RIKEN cDNA } \\
\text { 1810010M01 gene; Mm.21835; } \\
\text { BC031800) }\end{array}$ \\
\hline
\end{tabular}

Numbers indicate the count of serial analysis of gene expression (SAGE) tags per 50000.

$\uparrow \downarrow$ indicate a significant differential regulation by LF or HF feeding compared to fasting $(P \leq .05)$.

$*$ indicates the significant modulation in the HF compared to the LF group at the corresponding time point $(P \leq .05)$.

prevention and treatment. Motility and physical mechanisms involved in gastric-mediated satiety have been extensively studied and successfully targeted in recent years $[10,11]$. However, it is still unknown whether the gastric mucosa also releases any biochemical signal that may influence satiety in the very short term of meal consumption. In an attempt to explore this possibility, the serial analysis of gene expression (SAGE) method was used to identify the early transcriptional changes induced by a low-fat (LF) or high-fat (HF) meal in the gastric mucosa. The discovery potential of SAGE was determinant for choosing this technology instead of other comparable transcriptomic methods. SAGE, indeed, is a powerful and reliable sequencing-based technique [12] which allows to detect the regulation of novel transcripts as well as characterized genes, as we have already shown in a number of previous studies $[13,14]$.

\section{Materials and Methods}

2.1. Animals, Diet, and Sample Preparation. A total of 140 male C57BL6 mice (12-week-old) were purchased from Charles River Canada Inc. and were acclimated for two weeks. Low-fat diet (LF, Research Diet no. 12450B: 10\% calories from fat, $70 \%$ from carbohydrate, and 20\% from protein; $3.85 \mathrm{kcal} / \mathrm{g}$ ) and tap water were served ad libitum. In the last day of the acclimatization, the body weight 

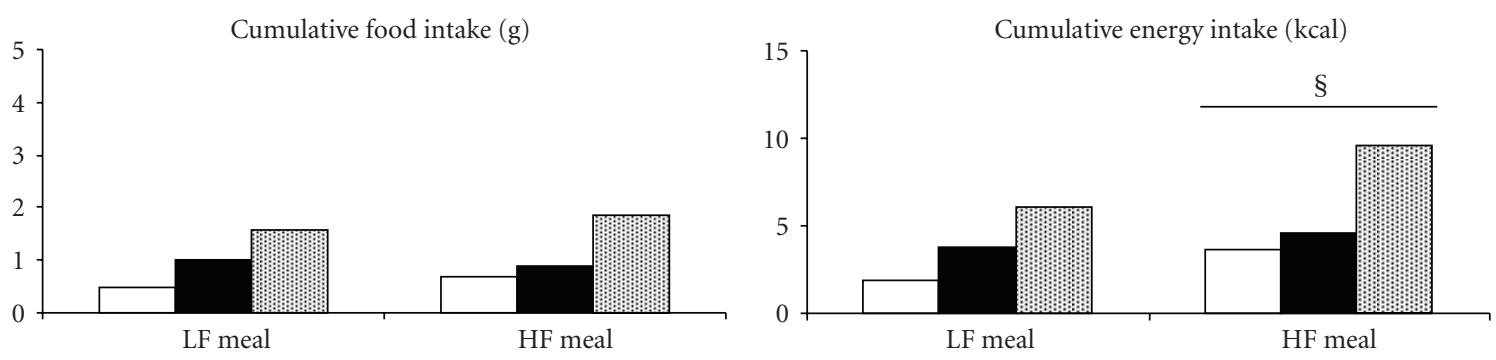
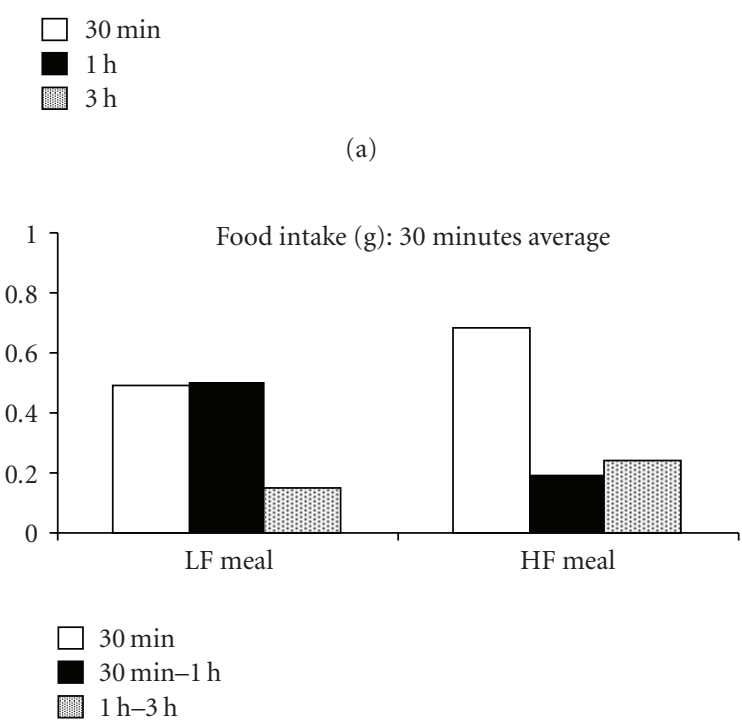

(c)

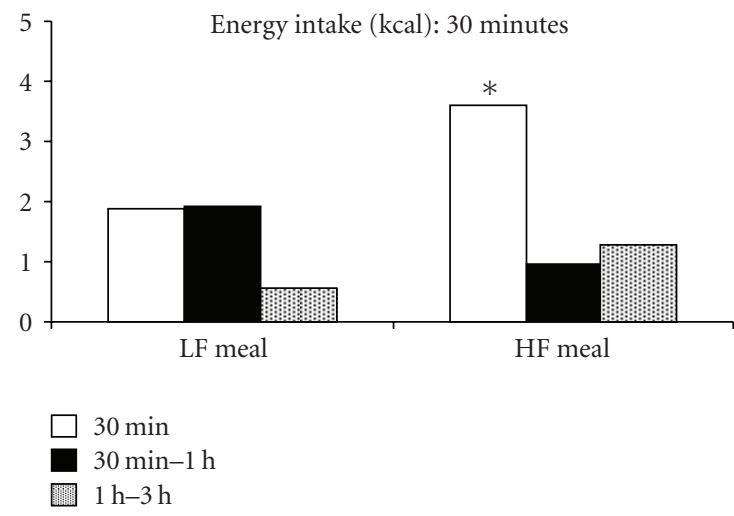

(d)

FIgURE 1: Food and energy intake of low-fat and high-fat meals: cumulative (a, b) and 30 minutes average (c, d) measurements. * Significantly different compared to low-fat $(\mathrm{LF})$ meal at the same time point $(P<.05)$. § Significant effect of the diet $(P<.05)$. Abbreviations: g, grams; kcal, kilocalories; LF, low fat; HF, high fat.

paired mice were randomly distributed into seven groups and fasted for 12 hours during darkness of the light cycle. On the experimental day, one group of fasted mice was sacrificed before the meal. The other mice were fed ad libitum with high-fat (HF, Research Diet no. 12492: 60\% calories from fat, $20 \%$ from carbohydrate, and 20\% from protein; $5.24 \mathrm{kcal} / \mathrm{g}$ ) or LF meal and sacrificed $30 \mathrm{~min}, 1 \mathrm{~h}$, and $3 \mathrm{~h}$ after the beginning of the meal. The amount of macronutrients and energy ingested was recorded. In total, seven groups of mice under isoflurane anesthesia (fasting, $\mathrm{HF} 30 \mathrm{~min} / 1 \mathrm{~h} / 3 \mathrm{~h}$, and LF $30 \mathrm{~min} / 1 \mathrm{~h} / 3 \mathrm{~h}$ ) were alternatively exsanguinated by cardiac puncture after cervical dislocation. Stomach was opened vertically and flushed clean with saline, and the mucosa was removed by scrapping with a glass microscope slide. The samples were rapidly frozen in liquid nitrogen and stored at $-80^{\circ} \mathrm{C}$ until RNA extraction. All animal experimentation was conducted in accordance with the requirements of the Canadian Council on Animal Care and approved by the Animal Protection Committee of Laval University.

2.2. Transcriptomic Analysis. The seven serial analyses of gene expression (SAGE) libraries were constructed as previously described [15]. Total RNA was isolated from pooled stomach mucosa for each group $(n=20)$ by Trizol (Invitrogen Canada Inc., Burlington, ON). The quality of total RNA was monitored by microcapillary electrophoresis (Bioanalizer 2100, Agilent Technologies, Mississauga, ON). Polyadenylated RNA was extracted (Oligotex mRNA Mini Kit, Qiagen Inc., Mississauga, ON), annealed with the biotin$5^{\prime}-\mathrm{T}_{18}-3^{\prime}$ primer, and converted to cDNA (cDNA synthesis kit, Invitrogen Canada Inc.). The resulting cDNAs were digested with NlaIII (New England BioLabs Ltd., Pickering, $\mathrm{ON}$ ), and the $3^{\prime}$ restriction fragments were isolated with streptavidin-coated magnetic beads (Dynal Biotech LLC, Brown Deer, WI) and separated into two populations. Each population was ligated to one of two annealed linkers and extensively washed to remove unligated linkers [15]. The tag beside the most $3^{\prime}$ NlaIII restriction site (CATG) of each transcript was released by digestion with BsmFI (New England BioLabs Ltd.). The blunting kit from Takara Bio Inc. (Otsu, Japan) was used for the blunting and ligation of the two tag populations. The resulting ligation products containing the ditags were amplified by PCR and digested with NlaIII. The band containing the ditags was extracted from the $12 \%$ polyacrylamide gel. The purified ditags were self-ligated to form concatemers using T4 ligase (Invitrogen Canada Inc.). The isolated $500 \mathrm{bp}$ to $1800 \mathrm{bp}$ concatemers were isolated by 
TABLE 2: Transcripts with defence/protection roles and other genes differentially modulated by feeding in the gastric mucosa.

\begin{tabular}{|c|c|c|c|c|c|c|c|c|c|c|c|c|c|}
\hline \multirow{2}{*}{ Tag } & \multirow{2}{*}{ Fasting } & \multicolumn{4}{|c|}{ Low fat } & & \multicolumn{6}{|c|}{ High fat } & \multirow{2}{*}{ Description } \\
\hline & & $30 \mathrm{~min}$ & $1 \mathrm{~h}$ & & $3 \mathrm{~h}$ & & $30 \mathrm{~min}$ & & $1 \mathrm{~h}$ & & $3 \mathrm{~h}$ & & \\
\hline \multicolumn{14}{|l|}{$\begin{array}{l}\text { Cellular defence/ } \\
\text { Protein modification }\end{array}$} \\
\hline CCAGGCCTTAC & 53 & 23 & 44 & & 11 & $\downarrow$ & 44 & & 47 & & 32 & & $\begin{array}{l}\text { Cysteine-rich protein } 1 \\
\text { (Mm.272368; NM_007763) }\end{array}$ \\
\hline TGTTCAGTTTT & 0 & 2 & 23 & $\uparrow$ & 0 & & 0 & & 8 & & 0 & & $\begin{array}{l}\text { Heat shock protein 1A-Hsp70 } \\
\text { 1A (Mm.6388; BC054782) }\end{array}$ \\
\hline TCTACACTGCC & 0 & 15 & 56 & $\uparrow$ & 7 & & 10 & & 45 & $\uparrow$ & 0 & & $\begin{array}{l}\text { EST Heat shock protein } \\
\text { 1B-Hsp70 1B (Mm.372314; } \\
\text { BP766094) }\end{array}$ \\
\hline TAACTGACAAT & 91 & 38 & 37 & & 26 & $\downarrow$ & 64 & & 66 & & 43 & & $\begin{array}{l}\text { Metallothionein } 2 \\
\text { (Mm.147226; BC031758)/EST } \\
\text { Phosphatidylinositol-4- } \\
\text { phosphate 5-kinase, type } 1 \\
\text { alpha-Pip5k1a (Mm.296409; } \\
\text { BU744153) }\end{array}$ \\
\hline AACGCTTTCTA & 81 & 27 & 46 & & 33 & & 34 & & 45 & & 11 & $\downarrow$ & $\begin{array}{l}\text { Placenta-specific } 8 \text { (onzin) } \\
(\mathrm{Mm} .34609 ; \mathrm{BC} 010789)\end{array}$ \\
\hline CAGGAGGAGTT & 28 & 13 & 21 & & 18 & & 22 & & 4 & & 41 & * & $\begin{array}{l}\text { Protein disulfide isomerase } \\
\text { associated } 3 \text { (Mm.263177; } \\
\text { BC033439) }\end{array}$ \\
\hline GTGTGCGCTGG & 10 & 0 & 0 & & 38 & & 6 & & 0 & & 0 & $*$ & $\begin{array}{l}\text { EST Elastase 2A (Neutrophil } \\
\text { elastase) (Mm.45316; } \\
\text { BM730866) }\end{array}$ \\
\hline TCGCTGCTTTA & 75 & 44 & 40 & & 11 & $\downarrow$ & 24 & & 23 & & 25 & & $\begin{array}{l}\text { EST WD repeat domain } 92 \\
(\mathrm{Mm} .298132 ; \mathrm{CO} 039767)\end{array}$ \\
\hline \multicolumn{14}{|c|}{ Regulatory mechanisms } \\
\hline TATTTCAGTGA & 0 & 6 & 8 & & 27 & $\uparrow$ & 12 & & 6 & & 5 & & $\begin{array}{l}\text { Adenylate cyclase } 6 \\
\text { (Mm.157091; NM_007405) }\end{array}$ \\
\hline GGCTGTCCTGT & 0 & 2 & 15 & & 13 & & 2 & & 6 & & 25 & $\uparrow$ & $\begin{array}{l}\text { DEAD (Asp-Glu-Ala-Asp) } \\
\text { box polypeptide } 17 \\
(\text { Mm.29644; BC096036) }\end{array}$ \\
\hline TCCTGAAGAGG & 2 & 8 & 31 & $\uparrow$ & 13 & & 12 & & 16 & & 16 & & $\begin{array}{l}\text { Furin (paired basic amino } \\
\text { acid cleaving enzyme) } \\
(\mathrm{Mm} .5241 ; \mathrm{BC} 048234)\end{array}$ \\
\hline AАTTTCTTCCT & 24 & 67 & 12 & & 26 & & 8 & * & 18 & & 2 & & $\begin{array}{l}\text { Major urinary protein } 1 / 2 \\
\text { (Mm.335875; BC099597); } \\
(\mathrm{Mm} .457981 \text {; AC:BC012259). }\end{array}$ \\
\hline CAGCAAATGAA & 6 & 6 & 0 & & 33 & & 4 & & 2 & & 0 & * & $\begin{array}{l}\text { EST Kallikrein } 1 \text { (Mm.142722; } \\
\text { BG871914) }\end{array}$ \\
\hline \multicolumn{14}{|l|}{ Others } \\
\hline AAAAATCATCG & 22 & 4 & 67 & & 62 & & 62 & & 76 & & 93 & $\uparrow$ & $\begin{array}{l}\text { NADH dehydrogenase 5, } \\
\text { mt-Nd5 (CDNA clone } \\
\text { IMAGE: 4910858; } \\
\text { Mm.455357; BC055066) }\end{array}$ \\
\hline GACCTGGAGCC & 30 & 23 & 8 & & 2 & $\downarrow$ & 14 & & 6 & & 7 & & $\begin{array}{l}\text { EST Ribosomal protein S14 } \\
(\mathrm{Mm} .43778 ; \text { AV212419) }\end{array}$ \\
\hline
\end{tabular}

Numbers indicate the count of serial analysis of gene expression (SAGE) tags per 50000.

$\uparrow \downarrow$ indicate a significant differential regulation by LF or HF feeding compared to fasting $(P \leq .05)$.

* indicates the significant modulation in the HF compared to the LF group at the corresponding time point $(P \leq .05)$.

agarose gel, and the resulting DNA fragments were ligated into the SphI site of pUC19 and cloned into OmniMAX 2T1 competent cells (Invitrogen Canada Inc.). White colonies were picked up, and the concatemer inserts were finally sequenced by the Applied Biosystems 3730 (Foster City, CA).
2.3. Bioinformatic Analysis. Sequence files were analyzed using the SAGEana program, a modification of SAGEparser [12]. Identification of the transcripts was obtained by matching the $15 \mathrm{bp}$ (sequence at the last CATG +11 bp tags) with SAGEmap, UniGene, and GenBank databases. Classification 

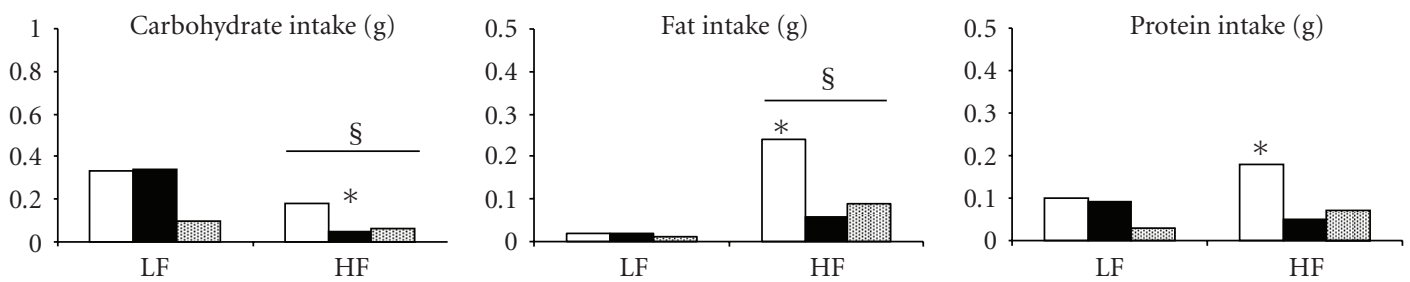

$$
\begin{aligned}
& \square 30 \mathrm{~min} \\
& \text { - } 30 \mathrm{~min}-1 \mathrm{~h} \\
& \square 1 \mathrm{~h}-3 \mathrm{~h}
\end{aligned}
$$

$\square 30 \mathrm{~min}$

- $30 \mathrm{~min}-1 \mathrm{~h}$
[ $1 \mathrm{~h}-3 \mathrm{~h}$

(b)

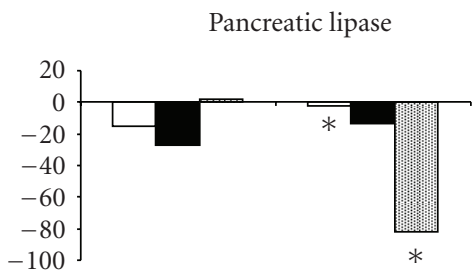

LF

HF

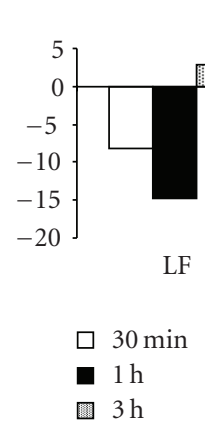

(d)

$$
\begin{aligned}
& \square 30 \mathrm{~min} \\
& \square 1 \mathrm{~h} \\
& \square 3 \mathrm{~h}
\end{aligned}
$$

(e)

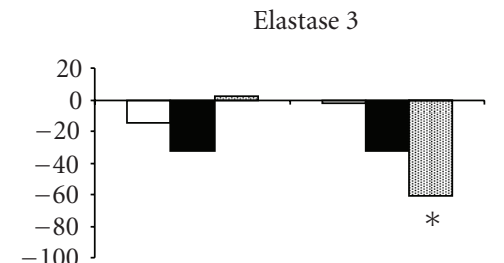

LF

HF

FIGURE 2: Thirty minutes average nutrient intake $(\mathrm{a}, \mathrm{b}, \mathrm{c})$ and the correspondent digestive enzyme-coding gene fold-change regulation by feeding $(\mathrm{d}, \mathrm{e}, \mathrm{f}) .{ }^{*}$ Significantly different compared to low-fat $(\mathrm{LF})$ meal at the same time point $(P<.05)$. $\S$ Significant effect of the diet $(P<.05)$. Abbreviations: g, grams; LF, low fat; HF, high fat.

of the transcripts was based upon the updated information of the genome directory [16] found at the TIGR website (http://www.tigr.org/), the SOURCE (http://genome-www5. stanford.edu/cgi-bin/source/sourceSearch), and the OMIM (http://www.ncbi.nlm.nih.gov/) as well as previously published literatures. We have previously shown that the SAGE method is very reproducible with $r^{2}=0.96$ between two SAGE libraries constructed from the same total RNA pool [12].

2.4. Validation by Quantitative Real-Time PCR (Q_RT-PCR). First strand cDNA was synthesized using $5 \mu \mathrm{g}$ of pooled RNA of each experimental group in a reaction containing $200 \mathrm{U}$ of Superscript III Rnase H-RT (Invitrogen Canada Inc.), 50 ng of random hexamers, $300 \mathrm{ng}$ of oligo- $\mathrm{dT}_{18}, 50 \mathrm{mM}$ Tris$\mathrm{HCl} \mathrm{pH} \mathrm{8.3,} 75 \mathrm{mM} \mathrm{KCl}, 3 \mathrm{mM} \mathrm{MgCl}, 5 \mathrm{mM}$ dithiothreitol, $0.5 \mathrm{mM}$ deoxynucleotides triphosphate, and $40 \mathrm{U}$ human RNase inhibitor (Roche) in a final volume of $50 \mu \mathrm{L}$. The resulting products were then treated with $1 \mu \mathrm{g}$ of Rnase A for 30 minutes at $37^{\circ} \mathrm{C}$ and purified thereafter with Qiaquick PCR purification kits (Qiagen). The cDNA corresponding to $20 \mathrm{ng}$ of total RNA was used to perform fluorescentbased real-time PCR quantification using the LightCycler real-time PCR apparatus (Roche Inc., Nutley, NJ) and the FastStart DNA Master SYBR green kit (Roche Diagnostics). Quantifications were conducted in triplicates. Reading of the fluorescence signal was taken at the end of the heating to avoid nonspecific signal. A melting curve was performed to assess nonspecific signals. Annealing temperature was selected based on contamination levels and melting curve results. Prior to mRNA quantification, RNA samples were also verified for genomic DNA contamination. Oligoprimer pairs that allow the amplification of approximately $250 \mathrm{bp}$ were designed by GeneTools software (Biotools Inc., Edmonton, $A B$ ) and their specificity was verified by BLAST in GenBank database. Gene name, GenBank accession numbers, and regions used for the primer pairs were the following: chymotrypsin-like elastase family member $3 \mathrm{~B}$ (elastase 3, Cela3b), NM_026419, 189-385; amylase 2a1, pancreatic (Amy2a1), NM_001042712, 848-1039; pancreatic lipase (Pnlip), NM_026925, 840-1067; major urinary protein 1 (Mup1), NM_031188, 127-405; protein disulfide isomerase associated 3 (Pdia3), BC033439, 994-1222; zymogen granule membrane protein 16 (Zg16), NM_026918, 348-522. The mRNA levels were calculated using a standard curve of crossing point $(\mathrm{Cp})$ versus logarithm of the quantity and expressed as the number of copies per microgram of total RNA [17]. The LightCycler 3.5 program provided by the manufacturer (Roche Inc.) was used to calculate the $\mathrm{Cp}$ according to the second derivative and double-correction method previously described by Luu-The et al. [17]. The standard curve with efficiency coefficient $E=2$ was established using known cDNA amounts of $0,10^{2}, 10^{3}, 10^{4}$, $10^{5}$, and $10^{6}$ copies of ATP synthase O subunit. 
2.5. Statistical Analysis. Food and macronutrient intakes were analyzed by the two-way ANOVA. When the ANOVA revealed a significant interaction between diet and time, the contrast analysis was performed to identify the significant difference between the HF and LF groups from the same time points $(P<.05)$. For the SAGE data, the comparative count display (CCD) test was used to identify the transcripts which were significantly differentially expressed $(P \leq .05)$ between the groups with more than a two-fold change, as previously described by Lash et al. [18]. The data were normalized to 50000 tags for presentation. Q_RT-PCR data were analyzed by the two-tailed Student's $t$-test $(P<.01)$ for the time points formerly determined by the SAGE method.

\section{Results}

3.1. Food Intake. Food and energy intakes are presented in Figure 1 as cumulative and 30 minutes average consumption. As expected, cumulative energy as well as protein and fat intakes were higher, whereas carbohydrate intake was lower in the HF groups compared to LF (Figure 2(a)). Interestingly, a distinct pattern of feeding behavior between LF- and HFfed mice can be observed by comparing the average 30 minutes consumption of the two groups (Figure 1(c)). Mice assigned to LF meal ate a moderate amount of food during one hour, after which their consumption decreased to a minimum intake. In contrast, the HF group consumed a large amount of meal in the first 30 minutes although the intake dropped in the following 30 minutes, reaching the minimum level at $1 \mathrm{~h}$. However, the HF-group mice ingestion increased again in the last two hours.

3.2. Transcriptomic Analysis. Seven SAGE libraries were generated to identify the transcripts differentially modulated in mouse gastric mucosa by the following experimental conditions: fasting; LF or HF meal at $30 \mathrm{~min}, 1 \mathrm{~h}$ and $3 \mathrm{~h}$ since the beginning of consumption (LF $30 \mathrm{~m} / 1 \mathrm{~h} / 3 \mathrm{~h}$ and $\mathrm{HF} 30 \mathrm{~m} / 1 \mathrm{~h} / 3 \mathrm{~h}$, resp.). Among the 56382 SAGE tag species detected, a total of 35 transcripts were significantly regulated by LF and HF feeding compared to fasting, whereas 19 were specifically modulated by HF compared to LF.

\subsubsection{Transcripts Coding for Digestive/Secretory Proteins.} The most represented group includes transcripts coding for digestive enzymes and secretory pathway components (Table 1). Among the modulated mRNAs were amylase 2a1, pancreatic lipase, carboxyl ester lipase, elastase 1 and 3, and carboxypeptidase A1 and B1. Globally, three of them have lipolytic functions, nine code for proteolytic enzymes and one gene is involved in carbohydrate digestion. In addition, two genes involved in zymogen granule secretion were regulated, namely syncollin and zymogen granule membrane protein 16. Interestingly, most of these genes showed a common pattern of regulation since their expression was downregulated at LF $30 \mathrm{~m}$ and $1 \mathrm{~h}$, as well as at $\mathrm{HF} 1 \mathrm{~h}$ and $3 \mathrm{~h}$, compared to fasting. Moreover, the expression of these transcripts tended to increase at LF $3 \mathrm{~h}$ though the upregulation was statistically significant only for six of them, such as amylase $2 \mathrm{a} 1$, chymotrypsinogen $\mathrm{B} 1$, and pancreatic lipase related protein 1 . Remarkably, for 13 out of the 15 tags considered, the specific differential regulation between LF $3 \mathrm{~h}$ and HF $3 \mathrm{~h}$ achieved statistical significance. There is, therefore, a common downregulation of these transcripts following both LF and HF feeding although a temporal delay between the two groups can be observed. In addition, 3 hours after the beginning of the LF meal, their transcription tended to increase at higher levels than those observed at the fasting state.

3.2.2. Cellular Defence Related and Other Transcripts Differentially Regulated by Feeding. Feeding significantly regulated eight transcripts with protective roles (Table 2). Among these, the mRNAs coding for the heat shock protein 70 (Hsp70) 1A and expressed sequence tag (EST) Hsp70 1B were both upregulated by the LF meal, and the latter also by the HF meal, at $1 \mathrm{~h}$ following the beginning of ingestion. Gene expressions of cysteine-rich protein 1, metallothionein 2, and EST WD repeat domain 92 were reduced at LF $3 \mathrm{~h}$ compared to fasting, whereas onzin mRNA levels significantly decreased at HF $3 \mathrm{~h}$. Moreover, HF specifically modulated the transcription of protein disulfide isomerase associated 3 and EST elastase 2A/neutrophil elastase, respectively, up- and downregulated at $3 \mathrm{~h}$.

The results also showed the differential regulation of two transcripts coding for proprotein convertase proteins (furin and kallikrein) and an interesting new candidate as potential regulator of energy metabolism, namely Mup 1 (Table 2). In addition, LF and HF feeding significantly regulated 12 novel transcripts with no match in public databases (Table 3). In particular, the tags GGAGAACAGCG and CTGACTCAAAT were specifically modulated by HF feeding compared to LF and could represent potential targets for further characterization studies.

3.3. Q_RT-PCR Confirmation of SAGE Results. To validate the SAGE results, the Q_RT-PCR analysis was also performed for some of the genes differentially regulated by feeding. The chosen genes are representative of the functional groups discussed. As presented in Figure 3, the Q_RT-PCR results globally confirmed the changes in expression level as well as the significant modulation highlighted by the SAGE method.

\section{Discussion}

4.1. Fasting and Feeding States Modulated Pancreas-Related Genes in the Stomach. The main regulated functional group is represented by digestive enzyme-coding genes, many of which are mostly expressed by the pancreas [19]. In addition, two transcripts involved in the secretory pathway, syncollin, and zymogen granule membrane protein 16 were also modulated. Many of the physiological changes induced by food intake should arise within minutes. Therefore, the digestive enzymes and regulatory factors are normally synthesized and packed in secretory granules at rest, ready to be released when food ingestion and appropriate neurohumoral stimuli occur. Following the meal, another cycle of synthesis and packaging 
TABLE 3: Novel transcripts differentially modulated by feeding in the gastric mucosa.

\begin{tabular}{|c|c|c|c|c|c|c|c|c|c|c|c|c|c|}
\hline \multirow{2}{*}{ Tag } & \multirow{2}{*}{ Fasting } & \multicolumn{5}{|c|}{ Low fat } & & \multicolumn{6}{|c|}{ High fat } \\
\hline & & $30 \mathrm{~min}$ & & $1 \mathrm{~h}$ & & $3 \mathrm{~h}$ & & $30 \mathrm{~min}$ & & $1 \mathrm{~h}$ & & $3 \mathrm{~h}$ & \\
\hline TTGTTGCTACT & 26 & 13 & & 19 & & 13 & & 16 & & 0 & $\downarrow$ & 11 & \\
\hline GGAGAACAGCG & 10 & 15 & & 13 & & 5 & & 4 & & 0 & & 29 & * \\
\hline CTGACTCAAAT & 4 & 0 & & 4 & & 26 & & 4 & & 0 & & 0 & * \\
\hline TCCTATTAAGC & 4 & 38 & $\uparrow$ & 37 & $\uparrow$ & 22 & & 18 & & 35 & $\uparrow$ & 23 & \\
\hline TTGGGGGAGGG & 10 & 36 & & 19 & & 16 & & 16 & & 23 & & 61 & $\uparrow$ \\
\hline CCTGCCCAGTA & 10 & 29 & & 42 & & 40 & & 14 & $\uparrow$ & 14 & & 61 & $\uparrow$ \\
\hline TACCATATACT & 22 & 25 & & 4 & & 0 & $\downarrow$ & 4 & & 20 & & 2 & \\
\hline TCTATGTCAGG & 2 & 8 & & 29 & $\uparrow$ & 9 & & 6 & & 12 & & 2 & \\
\hline GTGTCTGGTAA & 24 & 32 & & 89 & $\uparrow$ & 62 & & 56 & & 35 & & 43 & \\
\hline CACAAACATAT & 0 & 13 & & 8 & & 24 & $\uparrow$ & 10 & & 8 & & 14 & \\
\hline CGAACAAAAGA & 2 & 29 & $\uparrow$ & 19 & & 18 & & 24 & & 18 & & 14 & \\
\hline CCAGCAATCTT & 18 & 67 & & 85 & $\uparrow$ & 51 & & 82 & $\uparrow$ & 64 & & 45 & \\
\hline
\end{tabular}

Numbers indicate the count of serial analysis of gene expression (SAGE) tags per 50000.

$\uparrow \downarrow$ indicate a significant differential regulation by LF or HF feeding compared to fasting $(P \leq .05)$.

* indicates the significant modulation in the HF compared to the LF group at the corresponding time point $(P \leq .05)$.

prepares the zymogenic cells to the next secretory events [9]. Concordantly, the present results showed a decreased transcription of digestive enzyme-coding and secretory genes following the start of ingestion, when the cells are more likely to invest energy in secretion. Moreover, in the LF-fed mice, the reinduction of these genes that occurred 3 hours after the beginning of intake seems a reasonable event, particularly if referred to their feeding pattern (Figure 2). Conversely, the digestion of a high-calorie and high-energy density meal, including its rate of emptying from the stomach, normally takes a longer time to be accomplished $[20,21]$. The latter point may explain the delayed and prolonged downregulation of digestive transcripts in the HF group, which also suggests that the reinduction of transcription observed at LF $3 \mathrm{~h}$ may have started later in the HF-fed mice. Interestingly, though all the mice had ad libitum access to food, feeding behavior and total ingestion were dissimilar between LF and HF groups (Figures 1 and 2), possibly explaining the differences in the transcriptional regulation of digestive enzymes. However, the levels of digestive enzymes and secretory proteins might as well influence the intake. A physiological redundant excess of digestive capacity characterizes the GI system and guarantees the effectiveness of nutrition. Moreover, the excess capacity for nutrient uptake, including the excess of surface, specialized cells, digestive enzymes, and other secretory products, is proportionally related to body weight [9]. Hence, this may also contribute to compromise the efficient control of appetite/satiety balance in overweight and obese subjects. The stomach may represent a primary target for the control of meal size and satiation. Eventually, surgical options which physically affect gastric capacity and emptying mechanisms successfully modify the eating behavior and metabolic profile of obese patients [10] though they still are invasive and lifestyle-affecting methods [22]. Likewise, mechanisms other than mechanical may also affect gastric volume and emptying rates to regulate satiation during meal consumption. Presently, there still is a paucity of literature addressing the specific effects of HF intake on the neurohormonal control of gastric capacity and motility mechanisms. Therefore, the search for these pathways was the principal aim of the current study.

\subsection{Plausible Reasons for the Expression of Pancreatic Genes} in the Stomach. The observation that gastric mucosa could express pancreatic genes was unexpected. In particular, it would be useful to explain the specific role of these genes in the stomach and, most interestingly, their differential regulation in response to fasting and feeding. Considering the high level of transcription, such as for amylase $2 \mathrm{a} 1$ at fasting and LF $3 \mathrm{~h}$, the expression of these genes should entail a needed role in gastric mucosa. In contrast, it is hard to explain how the digestive enzymes, normally active at a neutral $\mathrm{pH}$, could conceivably work in such an acidic milieu. However, it should also be considered that these proteins are often released as precursors and eventually activated by specific signals or the appropriate $\mathrm{pH}$.

This was not the first time that the expression and activity of pancreas-related genes were detected in the stomach and other nonpancreatic components of the GI system. Terada and colleagues [19] had already showed the expression of alpha-amylase, trypsin, chymotrypsin, and pancreatic lipase in normal and pathologic epithelial cells of gastric mucosa by immunohistochemistry and western blotting. They had also proved their enzymatic activity in stomach specimens, although to a far lesser extent than in pancreas. In that report, the authors explained the presence of pancreatic enzymes in nonpancreatic tissues as a result of the common embryonic origin (foregut) shared by the gastroenteric tissues. In addition, the mRNA expression levels of representative genes have been further confirmed by Q_RT-PCR in the present study. It can be hypothesized that the digestive enzymes expressed by the gastric mucosa would combine with the bolus of homogenized and partially digested food that finally reaches the small intestine. In normal conditions, the digestive 


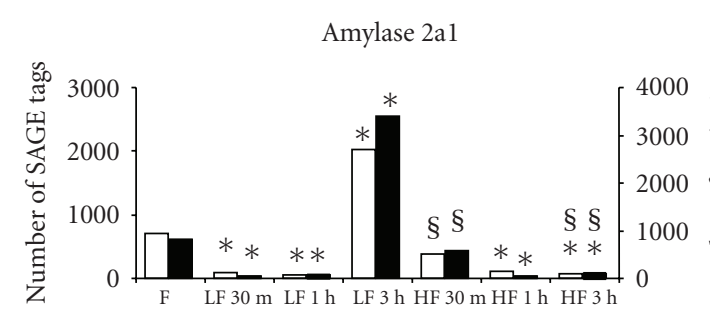

(a)

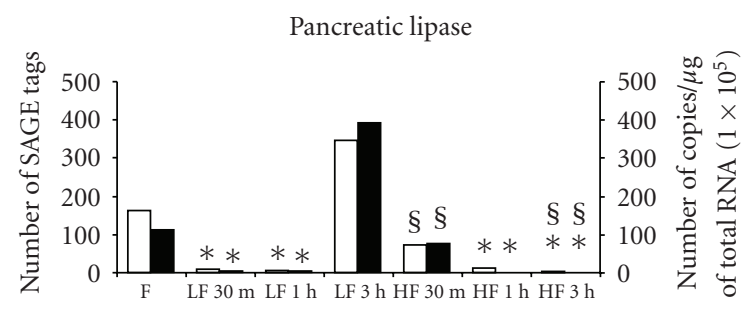

(c)

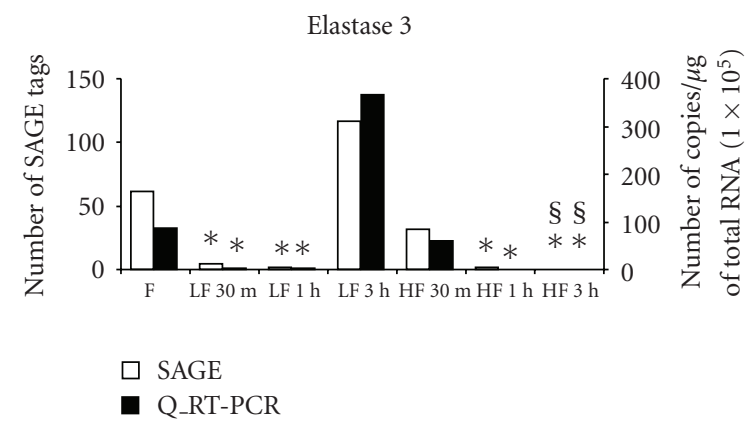

(e)

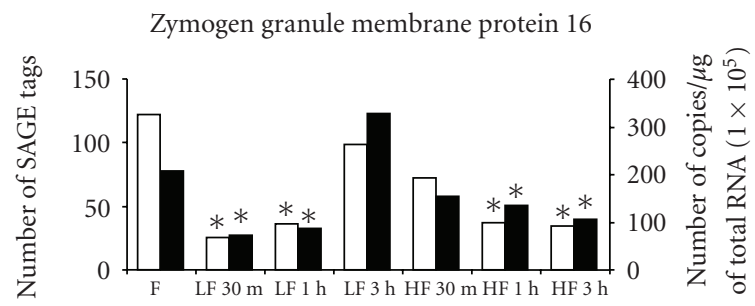

(b)

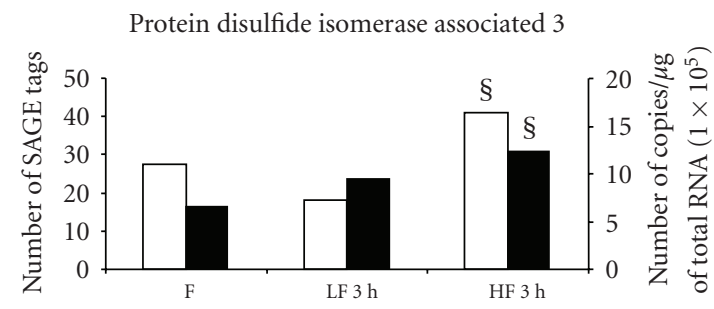

(d)

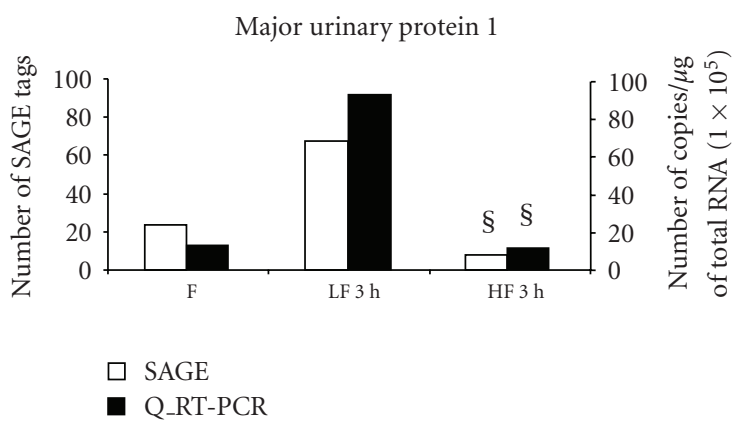

(f)

FIGURE 3: Serial analysis of gene expression (SAGE) and quantitative real-time PCR (Q_RT-PCR) results for some representative regulated genes. * Significantly different compared to fasting $(P<.01)$. § Significantly different compared to low-fat $(\mathrm{LF})$ meal at the same time point $(P<.01)$. Abbreviations: LF, low fat; HF, high fat.

enzymes would be in excess, but enough to guarantee the effectiveness of digestion in case of insufficient pancreatic secretion. The redundant production of these proteins along the digestive tract was also suggested by our previous study of the duodenum transcriptome, where analogue experimental conditions had been applied. In the intestine, the same pancreas-related transcripts were modulated $(n=9)$ [13] but showed the opposite trend, being upregulated at LF $1 \mathrm{~h}$ and HF $3 \mathrm{~h}$. Interestingly, in both the duodenal and gastric mucosa, the regulation of digestive gene expression presented a temporal delay between the LF and HF groups.

\subsection{LF and HF Modulated Genes Involved in the Protection} and Defense of Gastric Mucosa. Protection is one of the main functions and challenges of gastric mucosa. The mucosal epithelium is a primary barrier, which defends the whole organism from external dangerous agents eventually ingested. Moreover, uncontrolled acid secretion, inflammation, oxidative stress, and the epithelial damages consequently engendered can compromise the physical and functional integrity of the mucosal barrier [23]. Among the transcripts differentially regulated in the gastric mucosa, seven were related to defense and protection. Metallothionein $2[24,25]$, Hsp70 (1A and 1B) [26, 27], and protein disulfide isomerase associated 3 genes $[28,29]$ code for multiple-task proteins, which can show chaperone activity and/or be involved in cell redox homeostasis control and apoptosis regulation. The latter is a very important role, since gastric epithelium is subject to constant renewal. The epithelial cells, in fact, rapidly turnover (1-3 days in humans), undergoing a cycle of division and differentiation before succumbing to apoptosis $[9,30]$. In this study, EST Hsp70 1B was upregulated by both LF and HF at $1 \mathrm{~h}$, and the same trend was observed for hsp70 1A. However, for the latter, the HF $1 \mathrm{~h}$ increase did not reach a statistical significance. Interestingly, a polymorphism of Hsp70 1B gene has been recently associated with obesity-related traits [31], thus stimulating further questions about its acute modulation by food intake.

\subsection{Mup1, Already Found in Hypothalamus and Duodenum,} was Expressed in the Gastric Mucosa and Regulated by Feeding. In the present study, the gene coding for Mup1 was specifically downregulated at HF $30 \mathrm{~m}$ compared to LF. In previous transcriptomic studies conducted with the 
SAGE method, Mup1 gene was also significantly regulated by feeding in the duodenum mucosa and hypothalamus of mice $[13,14]$. The corresponding protein is a pheromone transporter normally expressed by the liver. However, recent studies in mice have surprisingly revealed that Mup1 is also involved in glucose and lipid metabolism [32], and that it might play an important role in the regulation of energy expenditure [33]. These findings raise the interest about the specific role of this molecule at the tissue level but also as a potential modulator of energy balance.

4.5. Other Interesting Genes Differentially Regulated by Feeding. Globally, the most regulated class of genes was the one coding for proteolytic enzymes, particularly the serine-protease type. This group of proteases is highly represented in nature and shows numerous and functionally diverse functions, ranging from digestion and coagulation to apoptosis and immunity [34]. In addition to the digestionrelated genes described above, feeding regulated two other transcripts coding for highly important serine proteases, namely kallikrein and furin. EST kallikrein 1 was specifically regulated by $\mathrm{HF} 3 \mathrm{~h}$ compared to $\mathrm{LF}$, whereas furin was downregulated at LF $1 \mathrm{~h}$. These two molecules act as proprotein convertases in distinct regulatory pathways. The first cleaves kininogen to produce kinin peptide [35], whereas furin processes the precursors of a large variety of proteins, including growth factors and receptors [36]. Interestingly, the specific pathways involving kallikrein-kinin $[37,38]$ and other proteins of furin family $[39,40]$ are presently being studied for their potential contribution to obesity and cardiovascular disorders.

\section{Conclusion}

The present study was the first to analyze the global transcriptional changes acutely induced in mouse stomach mucosa by feeding and, in particular, by different nutritional stimuli. The principal aim was to identify new signals specifically induced by HF intake in the short term of meal consumption. Given the weakest satiation power of HF compared to LF foods, these signals may represent potential pharmacological targets for the early modulation of appetite/satiety balance. In this study, both LF and HF regulated gene expression in gastric mucosa, and 17 known genes were differentially modulated by HF compared to LF intake. In addition, a number of novel tags were significantly regulated, some of which may be good objects for future characterization studies. However, a lower number of genes was regulated in the stomach compared to duodenum, when the same experimental conditions have been applied [13]. This may suggest that gastric mucosa has a restricted role in the acute regulation of food intake and mainly centered on meal initiation than meal size/termination control. Another plausible hypothesis is that satiation signals eventually raising from the mucosa could be induced earlier than $30 \mathrm{~min}$ after the beginning of the meal, at least at the transcriptional level. Although it is still uncertain whether gastric mucosa releases an early molecular signal specifically involved in satiation control, the present study contributed to highlight some potential mediators of this process. In addition, the characterization of novel regulated genes could stimulate future investigations. Since signals secreted by gastric mucosa may be the optimal targets for appetite control and obesity therapeutic strategies, further research efforts are deserved.

\section{Author's Contributions and Conflict of Interests}

The paper has been approved by all listed authors and there is no conflict of interest that would prejudice its impartiality. M. R. De Giorgio analyzed and interpreted the SAGE data, and drafted the paper. M. Yoshioka and J. StAmand conceived the study, designed it and critically revised the paper. J. St-Amand gave the final approval of the version to be published.

\section{Aknowledgments}

The authors would like to thank Mrs. Jean-Philippe Dionne, René Paradis, and Philippe Rigault for the bioinformatic support. This work was supported by the Heart and Stroke Foundation of Canada (HSFC) and the Canadian Institutes of Health Research (CIHR). Dr. J. St-Amand is a senior investigator supported by Fonds de la Recherche en Santé du Québec.

\section{References}

[1] D. Taubes, "Insulin resistance. Prosperity's plague," Science, vol. 325, no. 256, p. 260, 2009.

[2] S. K. Kumanyika, "Minisymposium on obesity: overview and some strategic considerations," Annual Review of Public Health, vol. 22, pp. 293-308, 2001.

[3] C. M. Apovian, "The causes, prevalence, and treatment of obesity revisited in 2009: what have we learned so far?" American Journal of Clinical Nutrition, vol. 91, no. 1, pp. 277S279S, 2010.

[4] P. J. Havel, "Peripheral signals conveying metabolic information to the brain: short-term and long-term regulation of food intake and energy homeostasis," Experimental Biology and Medicine, vol. 226, no. 11, pp. 963-977, 2001.

[5] J. E. Blundell and J. I. Macdiarmid, "Fat as a risk factor for overconsumption: satiation, satiety, and patterns of eating," Journal of the American Dietetic Association, vol. 97, no. 7, pp. S63-S69, 1997.

[6] L. J. Karhunen, K. R. Juvonen, A. Huotari, A. K. Purhonen, and K. H. Herzig, "Effect of protein, fat, carbohydrate and fibre on gastrointestinal peptide release in humans," Regulatory Peptides, vol. 149, no. 1-3, pp. 70-78, 2008.

[7] K. G. Murphy and S. R. Bloom, "Gut hormones and the regulation of energy homeostasis," Nature, vol. 444, no. 7121, pp. 854-859, 2006.

[8] P. K. Chelikani, A. C. Haver, and R. D. Reidelberger, "Ghrelin attenuates the inhibitory effects of glucagon-like peptide-1 and peptide $\mathrm{YY}(3-36)$ on food intake and gastric emptying in rats," Diabetes, vol. 55, no. 11, pp. 3038-3046, 2006.

[9] K. E. Barrett, Gastrointestinal Physiology, Lange Medical Books/McGraw Hill, 2006.

[10] J. Saliba, J. Wattacheril, and N. N. Abumrad, "Endocrine and metabolic response to gastric bypass," Current Opinion in 
Clinical Nutrition and Metabolic Care, vol. 12, no. 5, pp. 515521, 2009.

[11] D. Foschi, M. Lazzaroni, O. Sangaletti, F. Corsi, E. Trabucchi, and G. Bianchi Porro, "Effects of intramural administration of Botulinum Toxin A on gastric emptying and eating capacity in obese patients," Digestive and Liver Disease, vol. 40, no. 8, pp. 667-672, 2008.

[12] S. Dinel, C. Bolduc, P. Belleau et al., "Reproducibility, bioinformatic analysis and power of the SAGE method to evaluate changes in transcriptome," Nucleic Acids Research, vol. 33, no. 3, p. e26, 2005.

[13] M. Yoshioka, C. Bolduc, V. Raymond, and J. St-Amand, "High-fat meal-induced changes in the duodenum mucosa transcriptome," Obesity, vol. 16, no. 10, pp. 2302-2307, 2008.

[14] M. R. De Giorgio, M. Yoshioka, and J. St-Amand, "Feeding induced changes in the hypothalamic transcriptome," Clinica Chimica Acta, vol. 406, no. 1-2, pp. 103-107, 2009.

[15] J. St-Amand, K. Okamura, K. Matsumoto, S. Shimizu, and Y. Sogawa, "Characterization of control and immobilized skeletal muscle: an overview from genetic engineering," FASEB Journal, vol. 15, no. 3, pp. 684-692, 2001.

[16] M. D. Adams, A. R. Kerlavage, R. D. Fleischmann et al., "Initial assessment of human gene diversity and expression patterns based upon 83 million nucleotides of cDNA sequence," Nature, vol. 377, no. 6547, pp. 3-17, 1995.

[17] V. Luu-The, N. Paquet, E. Calvo, and J. Cumps, "Improved real-time RT-PCR method for high-throughput measurements using second derivative calculation and double correction," Biotechniques, vol. 38, no. 2, pp. 287-293, 2005.

[18] A. E. Lash, C. M. Tolstoshev, L. Wagner et al., "SAGEmap: a public gene expression resource," Genome Research, vol. 10, no. 7, pp. 1051-1060, 2000.

[19] T. Terada, Y. Kitamura, K. Ashida et al., "Expression of pancreatic digestive enzymes in normal and pathologic epithelial cells of the human gastrointestinal system," Virchows Archiv, vol. 431, no. 3, pp. 195-203, 1997.

[20] J. G. Moore, P. E. Christian, and J. A. Brown, "Influence of meal weight and caloric content on gastric emptying of meals in man," Digestive Diseases and Sciences, vol. 29, no. 6, pp. 513 519, 1984.

[21] O. Wisen, P. M. Hellstrom, and C. Johanssn, "Meal energy density as a determinant of postprandial gastrointestinal adaptation in man," Scandinavian Journal of Gastroenterology, vol. 28 , no. 8, pp. 737-743, 1993.

[22] S. S. Malinowski, "Nutritional and metabolic complications of bariatric surgery," American Journal of the Medical Sciences, vol. 331, no. 4, pp. 219-225, 2006.

[23] M. Ham and J. D. Kaunitz, "Gastroduodenal mucosal defense," Current Opinion in Gastroenterology, vol. 24, no. 6, pp. 665673, 2008.

[24] X. Li, LU. Cai, and W. Feng, "Diabetes and metallothionein," Mini-Reviews in Medicinal Chemistry, vol. 7, no. 7, pp. 761768, 2007.

[25] A. Formigari, P. Irato, and A. Santon, "Zinc, antioxidant systems and metallothionein in metal mediated-apoptosis: biochemical and cytochemical aspects," Comparative Biochemistry and Physiology C, vol. 146, no. 4, pp. 443-459, 2007.

[26] K. Rokutan, "Role of heat shock proteins in gastric mucosal protection," Journal of Gastroenterology and Hepatology, vol. 15, pp. D12-D19, 2000.

[27] R. Steel, J. P. Doherty, K. Buzzard, N. Clemons, C. J. Hawkins, and R. L. Anderson, "Hsp72 inhibits apoptosis upstream of the mitochondria and not through interactions with Apaf-1,"
Journal of Biological Chemistry, vol. 279, no. 49, pp. 5149051499, 2004

[28] T. Solda, N. Garbi, G. J. Hämmerling, and M. Molinari, "Consequences of ERp57 deletion on oxidative folding of obligate and facultative clients of the calnexin cycle," Journal of Biological Chemistry, vol. 281, no. 10, pp. 6219-6226, 2006.

[29] T. Panaretakis, N. Joza, N. Modjtahedi et al., "The cotranslocation of ERp57 and calreticulin determines the immunogenicity of cell death," Cell Death and Differentiation, vol. 15, no. 9, pp. 1499-1509, 2008.

[30] M. Lipkin, "Proliferation and differentiation of gastrointestinal cells,” Physiological Reviews, vol. 53, no. 4, pp. 891-915, 1973.

[31] G. Thorleifsson, G. B. Walters, D. F. Gudbjartsson et al., "Genome-wide association yields new sequence variants at seven loci that associate with measures of obesity," Nature Genetics, vol. 41, no. 1, pp. 18-24, 2009.

[32] Y. Zhou, L. Jiang, and L. Rui, "Identification of MUP1 as a regulator for glucose and lipid metabolism in mice," Journal of Biological Chemistry, vol. 284, no. 17, pp. 11152-11159, 2009.

[33] X. Hui, W. Zhu, YU. Wang et al., "Major urinary protein1 increases energy expenditure and improves glucose intolerance through enhancing mitochondrial function in skeletal muscle of diabetic mice," Journal of Biological Chemistry, vol. 284, no. 21, pp. 14050-14057, 2009.

[34] E. Di Cera, "Serine proteases," IUBMB Life, vol. 61, no. 5, pp. 510-515, 2009.

[35] J. Chao, G. Bledsoe, H. Yin, and L. Chao, "The tissue kallikrein-kinin system protects against cardiovascular and renal diseases and ischemic stroke independently of blood pressure reduction," Biological Chemistry, vol. 387, no. 6, pp. 665-675, 2006.

[36] K. Nakayama, "Furin: a mammalian subtilisin/Kex2p-like endoprotease involved in processing of a wide variety of precursor proteins," Biochemical Journal, vol. 327, no. 3, pp. 625-635, 1997.

[37] M. A. Mori, R. C. Araujo, F. C. G. Reis et al., "Kinin B receptor deficiency leads to leptin hypersensitivity and resistance to obesity," Diabetes, vol. 57, no. 6, pp. 1491-1500, 2008.

[38] A. Pizard, C. Richer, N. Bouby et al., "Genetic deficiency in tissue kallikrein activity in mouse and man: effect on arteries, heart and kidney," Biological Chemistry, vol. 389, no. 6, pp. 701-706, 2008.

[39] N. Scamuffa, F. Calvo, M. Chrétien, N. G. Seidah, and A. M. Khatib, "Proprotein convertases: lessons from knockouts," FASEB Journal, vol. 20, no. 12, pp. 1954-1963, 2006.

[40] S. Kovac, A. Shulkes, and G. S. Baldwin, "Peptide processing and biology in human disease," Current Opinion in Endocrinology, Diabetes and Obesity, vol. 16, no. 1, pp. 79-85, 2009. 


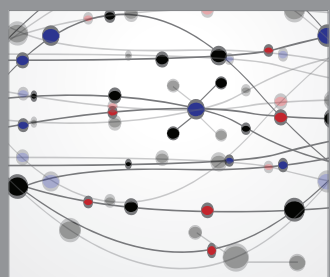

The Scientific World Journal
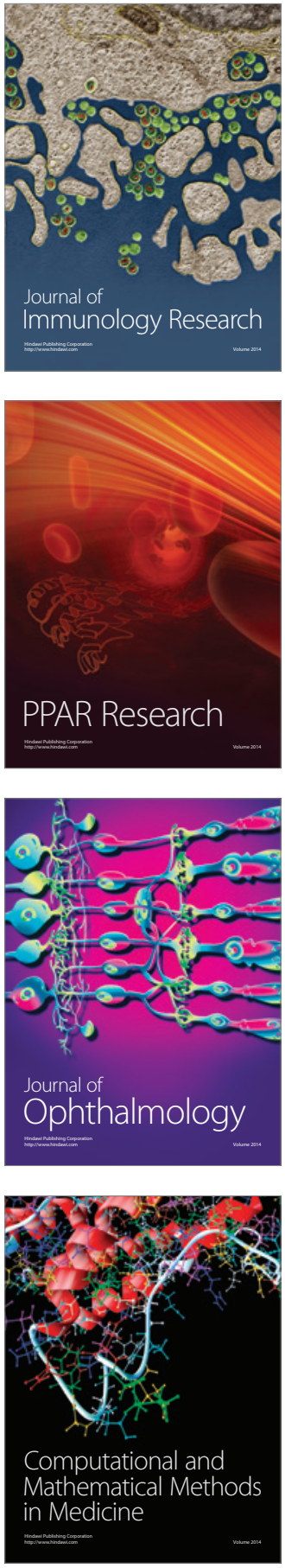

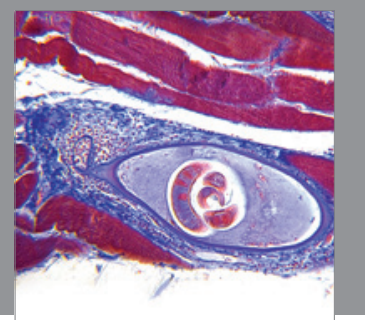

Gastroenterology

Research and Practice
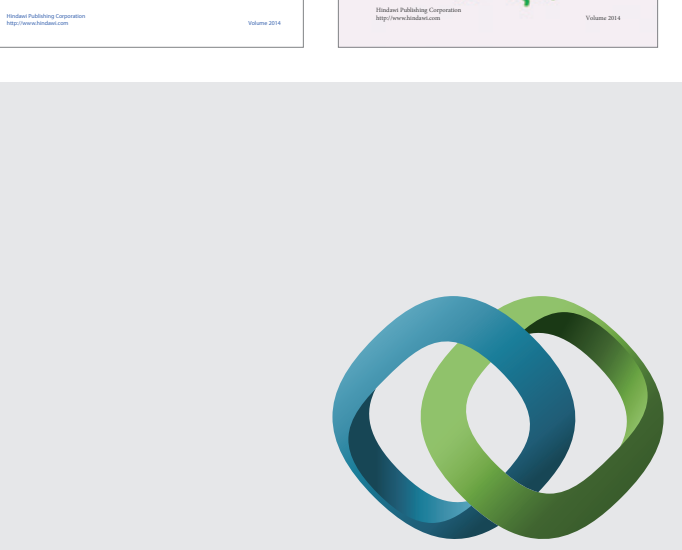

\section{Hindawi}

Submit your manuscripts at

http://www.hindawi.com
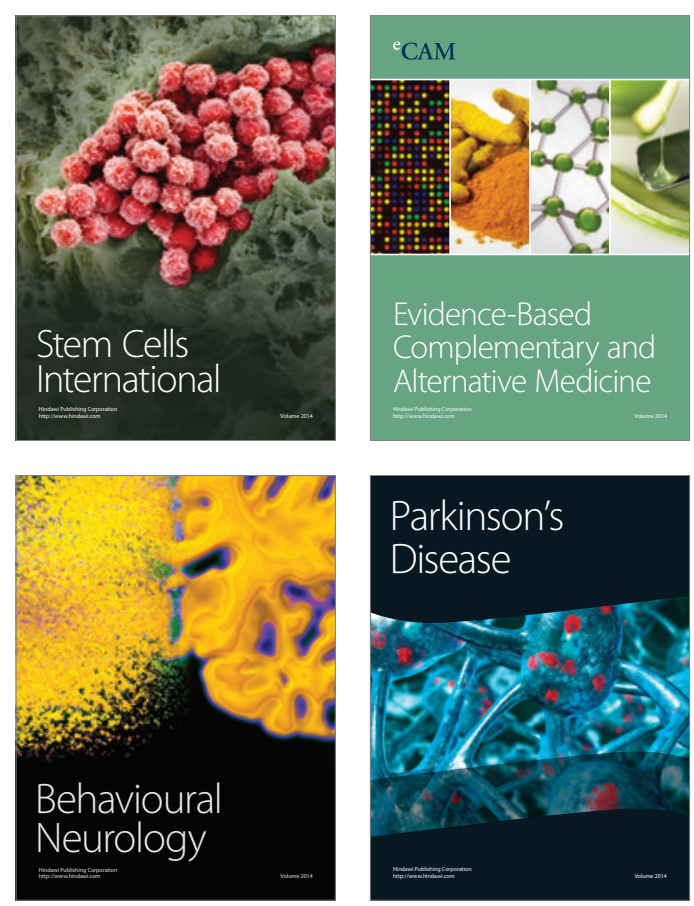

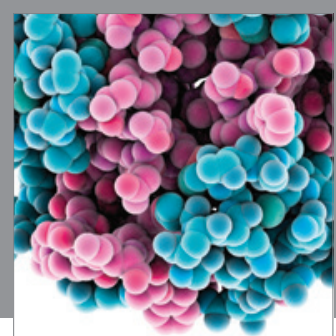

Journal of
Diabetes Research

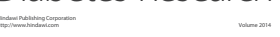

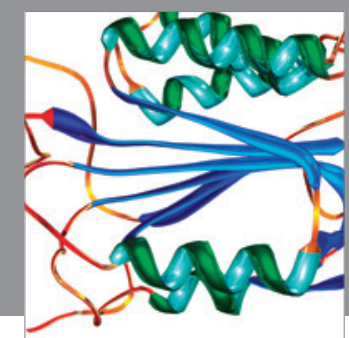

Disease Markers
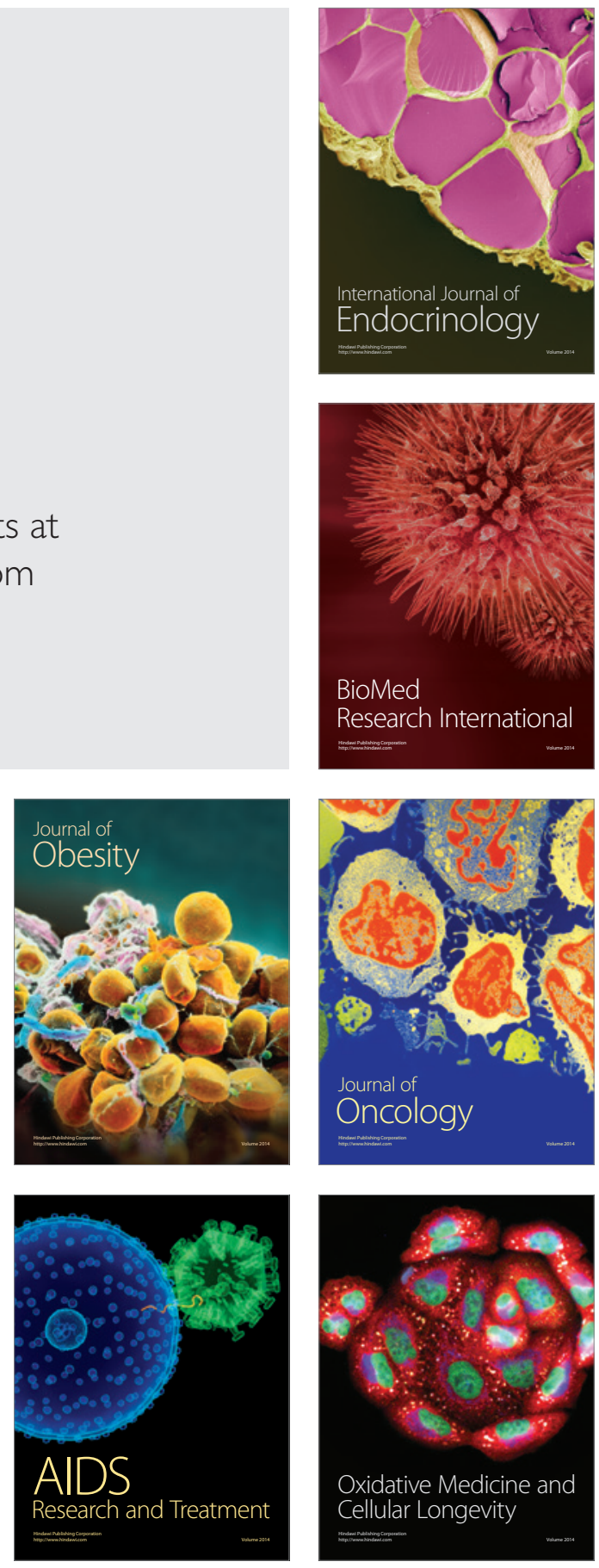